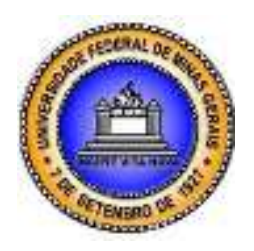

\title{
ANÁliSE DAS CONDIÇÕES DE ACESSIBILIDADE DE PESSOAS COM DEFICIÊNCIA AUDITIVA EM UNIDADES PÚBLICAS DE SAÚDE DO MUNICÍPIO DE MANAUS ${ }^{1}$
}

\author{
ANALYSIS OF THE CONDITIONS OF ACCESS TO PERSONS WITH DISABILITIES \\ HEARING IN HEALTH PUBLIC UNITS OF THE MANAUS
}

\section{ANÁLISIS DE LAS CONDICIONES DE ACCESO PARA PERSONAS CON AUDIENCIA DE UNIDADES DE SALUD PÚBLICA EN LA CIUDAD DE MANAUS}

\author{
LUIZ AUGUSTO DE CARVALHO FRANCISCO \\ SOARES \\ Universidade Federal de Minas Gerais/CEPEAD \\ las10@uol.com.br \\ LAYLA KELLY LOPES DE SOUZA \\ Universidade Federal do Amazonas - UFAM \\ laylaklopez@gmail.com
}

\author{
ARMANDO ARMANDO ARAÚJO DE SOUZA JUNIOR \\ Universidade Federal de Minas Gerais/CEPEAD \\ armando-jr07@bol.com.br
}

\author{
RICARDO JORGE DA CUNHA COSTA NOGUEIRA \\ Universidade Federal de Minas Gerais/CEPEAD \\ ricardo.nogueira3001@hotmail.com
}

\begin{abstract}
RESUMO
A maciça difusão dos direitos e deveres da sociedade, previstos pela Constituição Federal, tem alertado a população marginalizada sobre a necessidade de construção de políticas públicas inclusivas, além de ser parâmetro para a exigência do cumprimento de tais direitos. Nota-se que a parcela da população que apresenta algum tipo de deficiência não usufrui de tais direitos por falta de recursos físicos ou humanos. O presente trabalho tem como objetivo expor as condições de acesso de pessoas com deficiência auditiva no uso de serviços públicos de saúde. A metodologia desta pesquisa foi por abordagem quantitativa qualitativa dos dados coletados em cinco unidades de saúde administradas pelo Estado e Prefeitura, além de 30 pessoas com deficiência auditiva. Os dados coletados foram analisados e o conteúdo permitiu expressar os fenômenos estudados e a relação entre o que a Legislação Brasileira prevê e o que de fato é cumprido. Foi possível evidenciar que o uso dos serviços públicos de saúde por pessoas com deficiência auditiva no município de Manaus está em desencontro com o que é previsto por lei.
\end{abstract}

Palavras-Chave: direitos, constituição, acesso, saúde, deficiente auditivo.

\begin{abstract}
The diffusion of the rights and duties of society envisaged by the Constitution, has warned the marginalized population on the need to build inclusive public policies, as well as parameter to be a requirement to fulfill these rights. The share of the population has some type of disability does not use health services effectively due to lack of human or physical structure. This paper aims to expose the conditions of access for people with hearing loss in the use of public health services. The methodology for this research was quantitative approach qualitative data collected in five hospitals run by the state and City Hall, and 30 people with hearing loss. The collected data were analyzed and the contents allowed to express the phenomena studied and the relationship between the Brazilian law provides and what is actually done. The results showed that the use of public health services for people with hearing disabilities in the city of Manaus is in disagreement with what is prescribed by law.
\end{abstract}

KEYWORDS: rights, constitution, access, health, hearing disabilities.

\footnotetext{
${ }^{1}$ Submetido em 30 de maio de 2013. Aceito em 25 de outubro de 2013. O artigo foi avaliado segundo o processo de duplo anonimato e pelos editores. Editores responsáveis: Márcio Augusto Gonçalves e Lucas Maia dos Santos. Reprodução parcial ou total e trabalhos derivativos permitidos com a citação apropriada da fonte.
} 

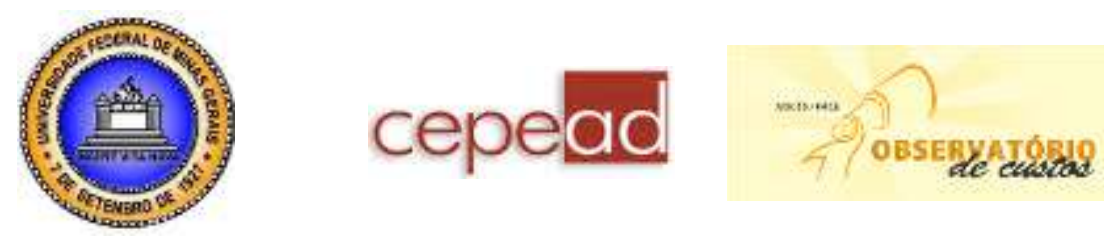

\section{RESUMEN}

La distribución masiva de los derechos y deberes en la sociedad, prevista por la Constitución, ha advertido a la población marginada en la necesidad de construir políticas públicas inclusivas, además de ser un parámetro a la obligación de garantizar estos derechos. Tenga en cuenta que la proporción de la población tiene algún tipo de discapacidad no goza de estos derechos por falta de recursos humanos y físicos. Este artículo tiene como objetivo exponer las condiciones de acceso de las personas con discapacidad auditiva en el uso de los servicios de salud pública. La metodología de esta investigación era el enfoque cuantitativo de datos cualitativos recogidos en cinco centros de salud administrados por el Estado y la Ciudad, y 30 personas con pérdida auditiva. Los datos recogidos fueron analizados y los contenidos permitidos para expresar los fenómenos estudiados y la relación entre la ley brasileña y ofrece lo que se hace en realidad. Los resultados mostraron que el uso de los servicios de salud pública de las personas con discapacidad auditiva en Manaus está en desacuerdo con lo prescrito por la ley.

PALABRAS CLAVE: derechos, constitución, acceso, salud, problemas de audición.

\section{INTRODUÇÃO}

Segundo dados do IBGE 2010, no Brasil, mais de 24 milhões de pessoas possuem algum tipo de deficiência, sendo na região norte a maior incidência: $16,7 \%$. Este número supera a média nacional e deste total, 5,5 milhões possuem deficiência auditiva. Em virtude destes dados e das garantias previstas pela Constituição Federal e Legislação Brasileira, foi realizado um estudo das condições de acessibilidade da pessoa surda em se tratando do sistema público de saúde no município de Manaus.

Na Declaração Universal dos Direitos Humanos e nos Pactos Internacionais de 2008, através das Nações Unidas, proclamou-se e concordou-se que toda pessoa faz jus aos direitos e liberdades ali estabelecidos, sem distinção de qualquer espécie reafirmando a universalidade, a indivisibilidade, a interdependência e a inter-relação dos direitos humanos e liberdades fundamentais, bem como a necessidade de que todas as pessoas com deficiência tenham a garantia de poder desfrutá-los plenamente, sem discriminação.

O artigo 196 da constituição federal estabelece que a saúde é direito de todos e dever do Estado, garantido mediante políticas sociais e econômicas que visem a redução do risco de doença e de outros agravos e ao acesso universal e igualitário às ações e serviços para sua promoção, proteção e recuperação.

Ao unirmos os dois conceitos estabelecemos que a pessoa com deficiência auditiva tem o direito de uso dos serviços de saúde e deve ter a garantia de que estes acessos sejam assegurados autonomamente. Para ratificar este direito a Lei Federal $\mathrm{n}^{\mathbf{o}} 10.098$ de 19 de dezembro de 2000, Lei da acessibilidade, estabelece, ainda, normas gerais e critérios básicos para a promoção da acessibilidade das pessoas com deficiência ou com mobilidade reduzida. E de fato, este estudo foi de fundamental importância para destacar se o que a legislação prevê é cumprido nas unidades públicas de saúde no município de Manaus.

\section{REFERENCIAL TEÓRICO}

\section{Acessibilidade}




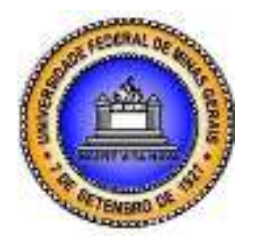

A acessibilidade integral é a possibilidade de uso com segurança e conforto de objetos, equipamentos e ambientes de maneira independente e autônoma pelo maior número possível de indivíduos. Segundo Sarraf (2007) estar acessível não diz respeito à eliminação de barreiras físicas somente, mas do campo das informações, das atitudes. De acordo com a legislação, no artigo segundo da Lei $n^{\circ} .10 .098$ de 19 de dezembro de 2000, acessibilidade remete ao alcance para utilização, com segurança e autonomia, dos espaços, mobiliários e equipamentos urbanos, das edificações, dos transportes e dos sistemas e meios de comunicação, por pessoa portadora de deficiência ${ }^{2}$ ou com mobilidade reduzida.

Acessibilidade diz respeito a locais, produtos, serviços ou informações efetivamente disponíveis ao maior número e variedade possível de pessoas independente de suas capacidades físico-motoras e perceptivas, culturais e sociais. Isto requer a eliminação de barreiras arquitetônicas, a disponibilidade de comunicação, de acesso físico, de equipamentos e programas adequados, de conteúdo e apresentação da informação em formatos alternativos. (BRASIL, 2008, p.256).

CASTRO et al (2011) afirmam que, no sistema de saúde, acessibilidade é o produto da relação entre a disponibilidade efetiva de serviços e o acesso por parte dos indivíduos a esses serviços. A discussão desses itens transcende a simples abordagem presença/ausência de obstáculos ao uso de serviços de saúde, alcançando um tema mais amplo e bastante importante em saúde pública: a equidade social.

\section{A Deficiência Auditiva}

Para Russo e Santos (1989), a surdez é um déficit sensorial com implicações na redução ou ausência da capacidade para ouvir sons, devido a fatores que afetam as orelhas externa, média e/ou interna. As perdas auditivas podem ser classificadas de acordo com o local da lesão, o grau da perda auditiva, época em que ocorreu e a origem. Segundo Bess \& Humes (1998), as perdas auditivas determinam diminuição da capacidade auditiva em diferentes graus de intensidade, podendo ser de caráter transitório ou definitivo e estacionário ou progressivo. Temos assim surdez congênita, aquelas que ocorreram antes ou durante o nascimento e adquiridas, as que aconteceram após o nascimento.

A perda auditiva traz consequências ao desenvolvimento psicossocial do surdo, diminuindo consideravelmente sua capacidade de adaptação social (BISOL, 2010). No atendimento médico e serviços de saúde, as pessoas com deficiência auditiva costumam expor barreiras que os excluem do direito à saúde. Para Chaveiro (2005), algumas das dificuldades apontadas são: a língua escrita, a ausência de profissionais capacitados para atender surdos e a presença do intérprete, valorizada em alguns momentos, enquanto, em outros, se torna invasiva.

\footnotetext{
${ }^{2}$ A terminologia correta : Pessoas com deficiência, uma vez que não se porta uma deficiência; não é como coisas que às vezes portamos e às vezes não portamos (por exemplo, um documento de identidade, um guarda-chuva. http://www.pessoacomdeficiencia.sp.gov.br/portal.php/terminologia)
} 

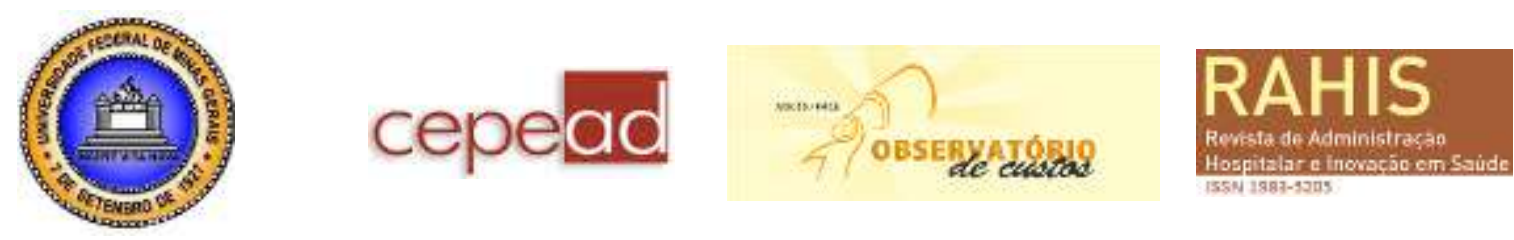

Apesar da escrita se constituir num fator facilitador na comunicação com pacientes surdos oralizados ${ }^{3}$ e com os que apresentam deficiência auditiva, é de pouca ajuda para os surdos pré-linguísticos, isto é, que ficaram surdos antes da aquisição da linguagem oral. Além destes fatores, Costa et al. (2009) afirmam que muitas das queixas são semelhantes às de ouvintes: a consulta ter que ser marcada com meses de antecedência; dificuldade em compreender certas palavras que os médicos usam; horários de usar os medicamentos; falta de paciência por parte dos profissionais de saúde; atendimento muito rápido; não manter contato visual com o paciente durante a consulta.

Além disso, outras preocupações se uniram em torno de temas gerais: visões conflitantes entre médicos e pacientes sobre ser surdo ou com deficiência auditiva; diferentes percepções sobre o que constitui uma comunicação eficaz (como a leitura labial, escrever notas e intérprete de linguagem gestual), a segurança de medicamentos e outros riscos colocados por comunicação inadequada, problemas de comunicação durante os exames físicos e procedimentos; dificuldades para interagir com o pessoal de escritório, incluindo salas de espera, e problemas com a comunicação de telefone. (IEZZONI et al., 2004).

Costa et al. (2009) afirmam que quando os pacientes surdos vão aos serviços particulares encontram médicos que conseguem boa comunicação, mesmo não conhecendo a Libras ou a cultura surda. Logo, se o médico tiver paciência, for atencioso, se interessar em compreender e ser compreendido por seu paciente, conseguirá ter uma boa comunicação, tanto com surdos quanto com ouvintes.

Uma das diretrizes do Aconselhamento em Saúde, situando o problema da comunicação, seja ele surdo ou idoso, que tenha dificuldade em articular as palavras ou com baixa escolaridade, indica que o médico deve ter a habilidade de se comunicar com os pacientes que possuam ou não essas características. O desenvolvimento dessas habilidades está previsto na Resolução $\mathrm{N}^{\circ} 4$ do Conselho Nacional de Educação / Conselho de Educação Superior, de 7 de novembro de 2001, que institui as diretrizes curriculares nacionais do curso de graduação em Medicina.

Segundo essa resolução, a formação dos médicos tem por objetivo dotar o profissional dos conhecimentos exigidos para o exercício das seguintes competências, entre outras: "comunicar-se adequadamente com os colegas de trabalho, os pacientes e seus familiares" e "informar e educar seus pacientes, familiares e comunidade em relação à promoção da saúde, prevenção e tratamento, e reabilitação das doenças, usando técnicas apropriadas de comunicação".

Algumas escolas médicas brasileiras, como a da Universidade Federal do Rio Grande do Sul, já se preocupam com o desenvolvimento de habilidades de comunicação por parte dos seus estudantes. Tais iniciativas solucionam outra problemática na comunidade surda, ligada diretamente à intimidade, já que muitos temem que a presença de um tradutor de Libras em consultas médicas possa expor alguns assuntos considerados confidenciais na própria

3 utilizam qualquer língua oral para se comunicar, na modalidade oral, oro-facial, também denominada de leitura labial e/ou leitura e escrita. Disponível em : http://www.todosnos.unicamp.br:8080/lab/linksuteis/acessibilidade-e-inclusao/textos/surdos-oralizados-e-nao-oralizados-uma-visao-critica/ 

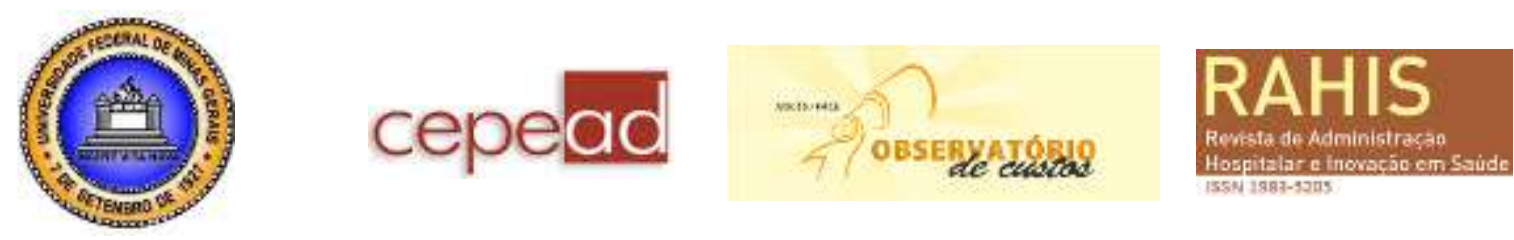

comunidade, da qual os intérpretes costumam fazer parte. Citam-se consultas com especialidades como: ginecologia, urologia, psicologia e psiquiatria.

\section{Legislação}

A Constituição Federal de 1988 assegura que todos devem ter equidade de direitos e acessibilidade: à educação, à saúde, ao trabalho, ao lazer, à previdência social, ao amparo, à infância e à maternidade, dignidade e a não discriminação. No capítulo VII, são estabelecidas garantias para criação de programas de prevenção e atendimento especializado para pessoas com deficiência física, sensorial ou mental.

De acordo com a legislação, a Lei $\mathrm{n}^{\circ}$ 10.098, de 19 de dezembro de 2000, conhecida como Lei de Acessibilidade, em seu Capítulo VII (da acessibilidade nos sistemas de comunicação e sinalização), artigo 18, dispõe que: "O Poder Público implementará a formação de profissionais intérpretes de escrita em braile, língua de sinais e de guiasintérpretes, para facilitar qualquer tipo de comunicação direta à pessoa portadora de deficiência sensorial e com dificuldade de comunicação", incluindo os serviços de saúde.

Já no artigo 21, o Poder Público, por meio dos organismos de apoio à pesquisa e das agências de financiamento, disponibiliza-se a fomentar programas destinados à promoção de pesquisas científicas voltadas ao tratamento e prevenção de deficiências; ao desenvolvimento tecnológico orientado à produção de ajudas técnicas para as pessoas portadoras de deficiência e à especialização de recursos humanos em acessibilidade.

No ambiente hospitalar, a legislação garante acesso à promoção da saúde, visita domiciliar, atendimento médico diferenciado e programas de saúde específicos, previstos na Lei 10.048, de 8 de novembro de 2000, de tal modo que estas pessoas tenham acesso à rede de serviços especializados em reabilitação e habilitação, bem como a tratamento adequado nos estabelecimentos de saúde. Configura-se crime, punível com reclusão de um a quatro anos e multa, recusar, retardar ou dificultar de alguma forma o acesso da pessoa com deficiência ao serviço de saúde, ou negligenciar assistência médico-hospitalar e ambulatorial, quando possível, a essas pessoas.

Em dezembro de 1999, através do Decreto $\mathrm{n}^{\mathbf{0}} 3.298$ - DOU de 21/12/99, foi a regulamentada, por meio da Lei $\mathrm{n}^{\circ} 7.853$, de 24 de outubro de 1989, a consolidação das normas de proteção e outras providências sobre a Política Nacional para a Integração da Pessoa Portadora de Deficiência.

A Lei $\mathrm{n}^{\circ} 7.405$, de 12 novembro de 1985, torna obrigatória a colocação do símbolo internacional de acesso em todos os locais e serviços que permitam sua utilização por pessoas com deficiências. O capítulo V desta lei inclui, "hospitais, clínicas e demais estabelecimentos do gênero"; sinalizando ainda no Art. $5^{\circ}$ que o símbolo deve ser colocado, obrigatoriamente, em local visível ao público.

Acerca do atendimento, o capítulo VII do Decreto $\mathrm{n}^{\circ}$ 5.626, de 22 de dezembro de 2005, dá garantia do direito à saúde das pessoas surdas ou com deficiência auditiva: "atendimento às pessoas surdas ou com deficiência auditiva na rede de serviços do $\mathrm{SUS}^{4}$ e das

\footnotetext{
${ }^{4}$ Sistema Único de Saúde
} 

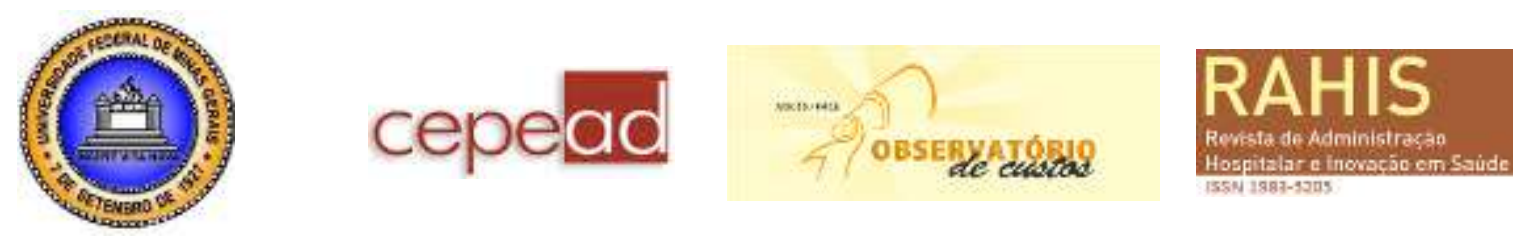

empresas que detêm concessão ou permissão de serviços públicos de assistência à saúde, por profissionais capacitados para o uso de Libras e sua tradução e interpretação"; além de "apoio à capacitação e formação de profissionais da rede de serviços do SUS para uso de Libras e sua tradução e interpretação".

O uso da Língua Brasileira de Sinais (Libras) ${ }^{5}$ está previsto na Lei $n^{\circ} 10.436$ de 24 de abril de 2002. "Art.1: É reconhecida como meio legal de comunicação e expressão a Língua Brasileira de Sinais - Libras e outros recursos de expressão a ela associados". O Decreto n ${ }^{\circ}$ 5.296 - de 2 de dezembro de 2004 - DOU de 3/12/2004 - Regulamenta as Leis nos 10.048, de 8 de novembro de 2000, que dá prioridade de atendimento às pessoas que especifica, e 10.098, de 19 de dezembro de 2000, que estabelece normas gerais e critérios básicos para a promoção da acessibilidade das pessoas com deficiência ou com mobilidade reduzida, e dá outras providências

Em 10.06.2002, o DOU publicou a Portaria do Ministério da Saúde n ${ }^{\mathbf{o}} 1.060$ Aprovando a Política Nacional de Saúde da Pessoa Portadora de Deficiência. "O Ministro de Estado da Saúde, no uso de suas atribuições, Considerando a necessidade de definição, no Setor Saúde, de uma política voltada para a reabilitação da pessoa portadora de deficiência na sua capacidade funcional e desempenho humano, de modo a contribuir para a sua inclusão plena em todas as esferas da vida social; Considerando a necessidade de proteger a saúde deste seguimento populacional, bem como prevenir agravos que determinem o aparecimento de deficiências; Considerando a conclusão do processo de elaboração da referida política, que envolveu a participação de diferentes setores governamentais e não governamentais envolvidos com o tema, e Considerando a aprovação da proposta da Política Nacional de Saúde da Pessoa Portadora de Deficiência na $104^{a}$ Reunião Ordinária do Conselho Nacional de Saúde".

\section{Associação Brasileira de Normas Técnicas - ABNT}

A ABNT, através do Fórum Nacional de Normatização, constituiu a NBR 9050:2004 Acessibilidade a Edificações, Mobiliário, Espaços e Equipamentos Urbanos. Esta norma estabelece critérios e parâmetros técnicos quanto a projetos, construções, instalações e adaptações em edificações, mobiliário, espaços e equipamentos urbanos a fim de normatizar os critérios e parâmetros técnicos sobre as condições de acessibilidade. Diversas condições de mobilidade e de percepção do ambiente foram consideradas, com ou sem a ajuda de aparelhos específicos, como: próteses, aparelhos de apoio, cadeiras de rodas, bengalas de rastreamento, sistemas assistivos de audição ou qualquer outro que venha a complementar as necessidades individuais das pessoas.

A ABNT 9050 define que, independentemente de idade, estatura, limitação de mobilidade ou percepção, esta Norma visa proporcionar à maior quantidade possível de pessoas, a utilização de maneira autônoma e segura do ambiente. Todos os espaços,

\footnotetext{
${ }^{5}$ Entende-se como Língua Brasileira de Sinais toda e qualquer forma de comunicação visual-motora que com estrutura gramatical própria constitui o sistema linguístico de transmissão de ideias fatos de pessoas surdas no Brasil.
} 

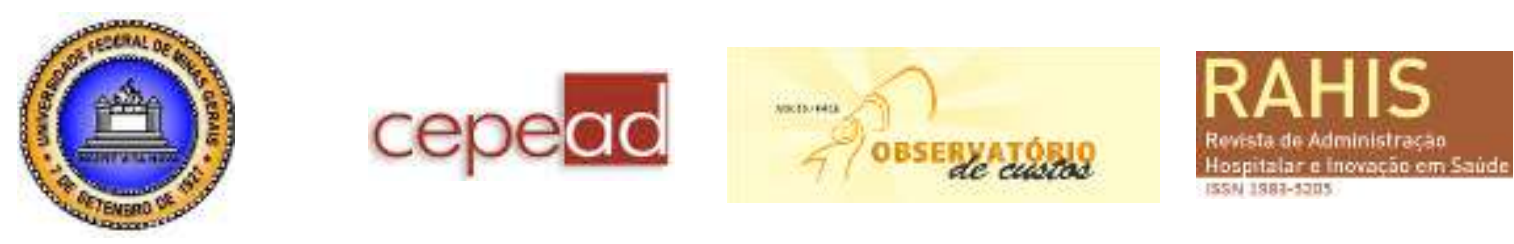

edificações, mobiliário e equipamentos urbanos que vierem a ser projetados, construídos, montados ou implantados, bem como as reformas e ampliações, devem atender ao disposto para serem considerados acessíveis.

Para fins de sinalização, a norma determina que a comunicação deve ser feita através de textos e figuras associadas indicativas de direção, bem como a utilizada para indicar as rotas de fuga e saídas de emergência das edificações, dos espaços e do ambiente urbano, ou para alertar quanto a um perigo iminente. Além das referências iconográficas, o símbolo internacional de acesso, deve indicar a acessibilidade aos serviços e identificar espaços, edificações, mobiliário e equipamentos urbanos onde existem elementos acessíveis ou utilizáveis por pessoas com deficiência auditiva. Esta sinalização deve ser afixada em local visível ao público, principalmente em entradas/recepções.

Sobre a legibilidade, deve haver contraste entre a sinalização visual (texto ou figura e fundo) e a superfície sobre a qual ela está afixada, cuidando para que a iluminação do entorno não prejudique a compreensão da informação; Os textos e figuras, bem como o fundo das peças de sinalização, devem ter acabamento fosco, evitando-se o uso de materiais brilhantes ou de alta reflexão; A visibilidade da combinação de cores pode ser classificada de forma decrescente em função dos contrastes. Recomenda-se a utilização de letras sem serifa, evitando-se padrões ou traços internos, fontes itálicas, recortadas, manuscritas, com sombras, com aparência tridimensional ou distorcidas (aparentando ser excessivamente largas, altas ou finas).

Sobre a representação de figuras, devem atender às seguintes condições: contornos fortes e bem definidos; simplicidade nas formas e poucos detalhes; forma fechada, completa, com continuidade; estabilidade da forma e simetria, já sobre dimensionamento (sinalização interna dos ambientes), a dimensão mínima das figuras deve ser de $15 \mathrm{~cm}$, considerando a legibilidade a uma distância máxima de $30 \mathrm{~m}$.

Os alarmes vibratórios devem estar associados e sincronizados aos alarmes visuais intermitentes, de maneira a alertar as pessoas com deficiência auditiva. Informações sonoras verbais podem ser digitalizadas ou sintetizadas, e devem ter as seguintes características: conter apenas uma oração - uma sentença completa, com sujeito, verbo e predicado, nesta ordem; estar na forma ativa e não passiva; estar na forma imperativa.

Na sinalização de portas deve haver informação visual (número da sala, função etc.) ocupando área entre $1,40 \mathrm{~m}$ e $1,60 \mathrm{~m}$ do piso, localizada no centro da porta ou na parede adjacente, ocupando área a uma distância do batente entre $15 \mathrm{~cm}$ e $45 \mathrm{~cm}$.

Já sobre as condições gerais de sinalização de emergência devem atender aos seguintes critérios: as rotas de fuga e as saídas de emergência devem ser sinalizadas com informações visuais; nas escadas que interligam os diversos pavimentos, inclusive nas de emergência, junto à porta corta-fogo, deve haver sinalização visual informando o número do pavimento; a mesma sinalização pode ser instalada nos corrimãos; em saídas de emergência devem ser instalados alarmes visuais, bem como os alarmes vibratórios, associados e sincronizados.

\section{METODOLOGIA}



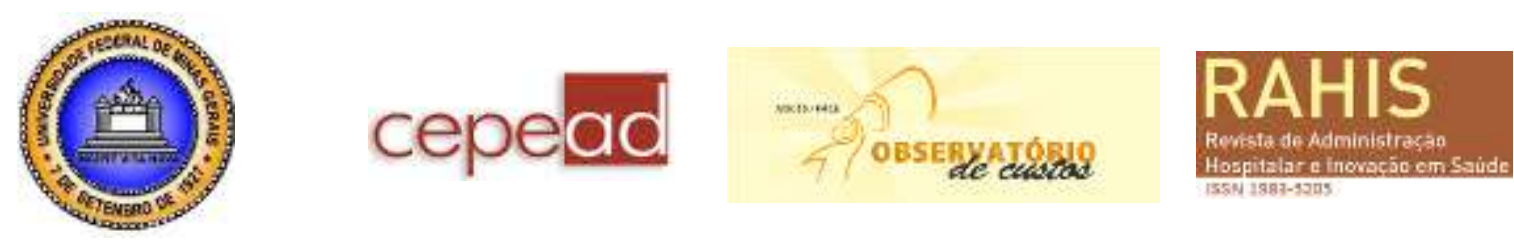

Os métodos qualitativos de pesquisa social focalizam as particularidades e as especificidades dos grupos estudados: valores, crenças, representações, hábitos, atitudes e opiniões. Mayring (2002) apresenta seis delineamentos da pesquisa qualitativa: estudo de caso, análise de documentos, pesquisa-ação, pesquisa de campo, experimento qualitativo e avaliação qualitativa. Bardin (1977) afirma que na analise qualitativa o que serve de informação é a presença ou ausência de uma dada característica de conteúdo ou de um conjunto de características num determinado fragmento de mensagem.

Já em se tratando da possibilidade de generalizar os resultados, o método quantitativo atua em níveis de realidade e tem como objetivo trazer à luz: dados, indicadores e tendências observáveis (MINAYO \& SANCHES, 1993). Bardin (1977) esclarece que, na análise quantitativa, o que serve de informação é a frequência com que surgem certas características de conteúdo.

A primeira estratégia - da pesquisa qualitativa - implica em relativa falta de controle de variáveis estranhas ou, ainda, a constatação de que não existem variáveis interferentes e irrelevantes. Todas as variáveis do contexto são consideradas como importantes. Na segunda estratégia - da pesquisa quantitativa - tenta-se obter um controle máximo sobre o contexto, inclusive produzindo ambientes artificiais com o objetivo de reduzir ou eliminar a interferência de variáveis interferentes e irrelevantes (GÜNTHER, 2006). Para fins de realização desta pesquisa, as duas estratégias foram utilizadas de forma a complementar as limitações de cada uma, caso fossem utilizadas de forma isolada.

Os sujeitos desta pesquisa são dez das unidades públicas de saúde do município de Manaus, representadas pelas Policlínicas. Cinco administradas pelo Município e cinco pelo Estado em todas as zonas da cidade: norte, sul, leste, oeste e centro. As policlínicas atendem diversas especialidades de saúde e o atendimento é feito através de consultas agendadas, na qual o paciente pode fazer o agendamento mediante encaminhamento médico.

Para execução de pesquisas sociais, é comum se trabalhar com uma pequena parte do universo (amostragem). Para esta pesquisa, foi utilizada a amostra do tipo acessibilidade.

Constitui o menos rigoroso de todos os tipos de amostragem. Por isso mesmo é destituída de qualquer rigor estatístico. O pesquisador seleciona os elementos a que tem acesso, admitindo que estes possam, de alguma forma, representar o universo. Aplica-se este tipo de amostragem em estudos exploratórios ou qualitativos, onde não é requerido elevado nível de precisão. (GIL 2008, p.94).

Para Gil (2008) questionário é a técnica de investigação composta por um conjunto de questões que são submetidas a pessoas com o propósito de obter informações. Construir um questionário consiste basicamente em traduzir objetivos da pesquisa em questões específicas. As respostas a essas questões é que irão proporcionar os dados requeridos para descrever as características da população pesquisada ou testar as hipóteses que foram construídas durante o planejamento da pesquisa.

Já a entrevista com roteiro estruturado desenvolve-se a partir de uma relação fixa de perguntas, cuja ordem e redação permanece invariável para todos os entrevistados, que geralmente são em grande número (GIL, 2008). Entre as principais vantagens das entrevistas 

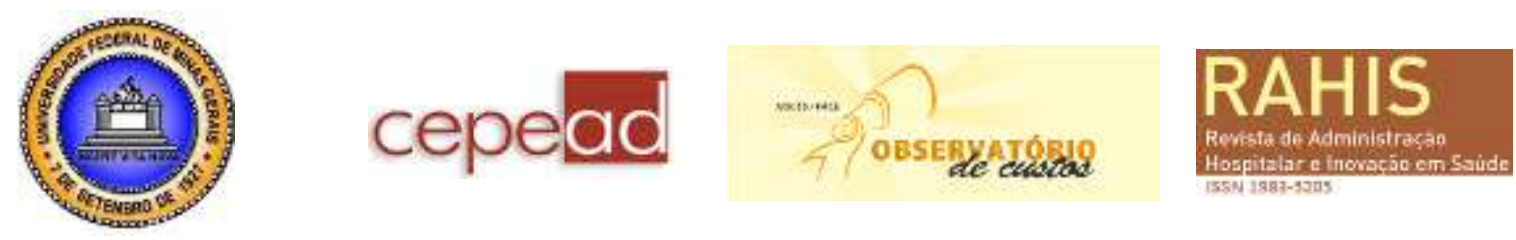

estruturadas estão a sua rapidez e a possibilidade de análise estatística dos dados, já que as respostas obtidas são padronizadas.

Os resultados foram traduzidos e transcritos para um questionário estruturado e posteriormente aplicou-se a técnica descrita por Bardin (1977), sob a designação de análise temática ou categórica, que consiste na decomposição de textos em unidades e depois classificação por reagrupamento. Esta análise prevê três etapas de execução: análise prévia, que consiste na organização do material, operacionalização e sistematização, escolha dos documentos, formulação de hipóteses, objetivos e elaboração de indicadores e leitura flutuante; análise exploratória, que consiste em codificações e classificações, caracterizandose por ser uma fase longa e fastidiosa e exigindo o trabalho de uma equipe, na qual seus membros atuam como juízes do trabalho de codificação e classificação temática; tratamento dos resultados obtidos e interpretação, que consiste na tabulação e aplicação de técnicas descritivas de análise.

\section{RESULTADOS DA PESQUISA}

Os dados do estudo refletem as dificuldades de acesso das pessoas com deficiência auditiva nas unidades de saúde, tanto nas administradas pelo Estado quanto pela Prefeitura no Município de Manaus. A princípio, foram estipuladas que participassem da pesquisa dez unidades de saúde, duas de cada uma das cinco zonas da cidade: norte, sul, leste, oeste e centro, sendo uma unidade de saúde (policlínica) administrada pelo Estado e uma administrada pela Prefeitura em cada zona. No entanto a pesquisa foi realizada em somente cinco das dez unidades predeterminadas.

$\mathrm{Na}$ Tabela 1 são apontados os números e percentuais equivalentes ao entendimento das necessidades básicas de deficientes auditivos e ainda à disponibilidade ou não dos serviços e condições amparadas por lei e normatizadas pela ABNT para o atendimento adequado aos usuários com deficiência auditiva em ambientes hospitalares. Quanto aos instrumentos de coleta de dados utilizados, optou-se por utilizar um questionário com dez questões e entrevista com roteiro estruturado.

Os resultados obtidos através de aplicação de questionários foram analisados com a utilização de procedimentos estatísticos descritivos, com objetivo básico de sintetizar uma série de valores de mesma natureza, permitindo dessa forma que se tenha uma visão global da variação desses valores através de tabelas, gráficos e de medidas descritivas.

\begin{tabular}{|c|c|c|c|c|}
\hline \multicolumn{5}{|l|}{ Itens observados } \\
\hline & \multicolumn{2}{|c|}{ Sim } & \multicolumn{2}{|c|}{ Não } \\
\hline & $\mathrm{n}$ & $\%$ & $\mathrm{n}$ & $\%$ \\
\hline Equipe de recepção sabe distinguir o que é Libras & 3 & 60 & 2 & 40 \\
\hline O símbolo internacional da surdez está exposto em locais de grande circulação & 0 & 0 & 5 & 100 \\
\hline Há atendimento prioritário para pessoas com deficiência auditiva & 5 & 100 & 0 & 0 \\
\hline Há sistema de marcação de consultas que o paciente pode fazer pela internet & 0 & 0 & 5 & 100 \\
\hline Há central telefônica para deficientes au ditivos & 0 & 0 & 5 & 10 \\
\hline o "chamamento" ao consultório é eletrônico visual & 1 & 20 & 4 & 80 \\
\hline Há sinalização para rotas de fuga e saídas de emergência em texto e figuras associadas & 1 & 20 & 4 & 80 \\
\hline A unidade disponibiliza interprete de Libras no horário de atendimento & 1 & 20 & 4 & 80 \\
\hline Nas portas internas constam informações visuais (número da sala, função, etc) & 5 & 100 & 0 & 0 \\
\hline Algum dos funcionários faz curso de capacitação acerca de deficientes auditivos & 0 & 0 & 5 & 100 \\
\hline
\end{tabular}



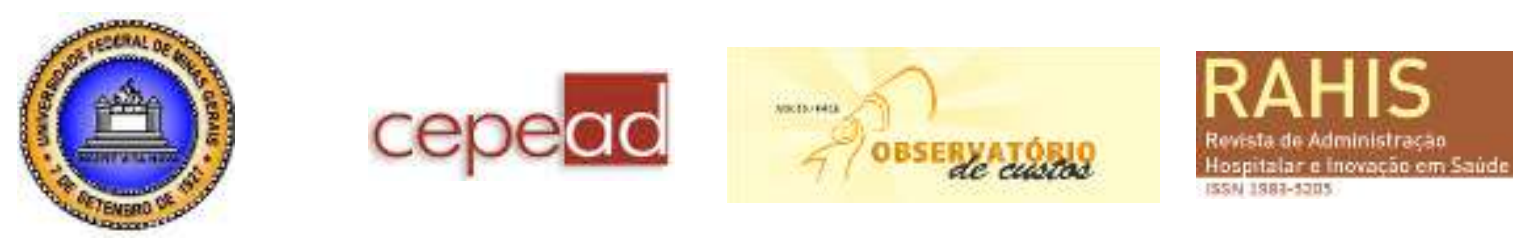

Tabela 1. Demonstrativo das condições de acessibilidade para deficientes auditivos nas unidades de saúde em Manaus.

Fonte: Dados da Pesquisa, 2012.

Desde dezembro de 2000, a Lei ${ }^{\circ}$ 10.098, conhecida como Lei de Acessibilidade, em seu Capítulo VII (da acessibilidade nos sistemas de comunicação e sinalização), artigo 18 dispõe que o Poder Público implementará a formação de profissionais intérpretes de língua de sinais para facilitar qualquer tipo de comunicação direta à pessoa com deficiência auditiva e dificuldade de comunicação. No entanto a pesquisa nos mostra que em nenhuma das unidades os profissionais que nela atuam fizeram ou estão fazendo algum tipo de capacitação voltada ao atendimento de pessoas com deficiência auditiva, tampouco disponibilizam interpretes nos horários de atendimento. A única unidade que informou disponibilizar esclareceu: "nossa estagiária de pedagogia sabe Libras, ela fica na unidade das $13 \mathrm{~h}$ às $17 \mathrm{~h}$, e dá suporte quando necessário".

Sarraf (2007) define como acessibilidade o processo de eliminação de barreiras, não só físicas, mas do campo das informações, das atitudes. A pesquisa nos levou a constatar que em se tratando de informações, em $60 \%$ das unidades a equipe de recepção não soube explicar o que é Libras, e chegaram até a confundir com Braile.

Quanto à perspectiva dos usuários surdos das unidades de saúde, foram realizadas entrevistas no universo de 30 pessoas com deficiência auditiva, cuja faixa etária varia de 11 a 41 anos, sendo 18 mulheres e 12 homens, escolhidos aleatoriamente dentro de uma perspectiva de amostra não probabilística por conveniência de pesquisa qualitativa. Das mulheres, cerca de $70 \%$ nasceu surda (12 delas), e sobre os homens, $41 \%$, adquiriu a surdez por motivos diversos, entre eles doenças, como a meningite, o que corresponde a $5 \%$ dos entrevistados homens. Todos se comunicam através da língua de sinais, português escrito ou leitura labial.

Com o intuito de descrever e analisar a percepção destes usuários em se tratando do atendimento nas unidades de saúde e das condições físicas destes espaços para receber um deficiente auditivo, foram realizadas entrevistas acerca das principais dificuldades encontradas. Todos os entrevistados relataram que um dos maiores problemas enfrentados é a falta de comunicação, porque não conseguem ser compreendidos através do uso da Língua Brasileira de Sinais, uma vez que não têm conhecimento de que exista unidade pública de saúde no município que disponibilize interprete, causando a dependência de um acompanhante sempre que for necessário utilizar o serviço. O percentual de avaliações negativas do encontro com profissionais de saúde representou $57 \%$ das respostas dos surdos oralizados; $65 \%$ dentre os bilíngues; e $79 \%$ no grupo de surdos que se comunicam através da língua de sinais.

$\mathrm{Na}$ transcrição e edição das entrevistas, foram realizados ajustes gramaticais em função da linguagem coloquial empregada pelos entrevistados. Sobre percepções conflituosas entre médicos e pacientes sobre surdez e deficiência Auditiva: 
"Uma amiga foi ao hospital com muita dor de barriga, o médico deu remédio pra cólica, não resolveu, depois descobriram que ela estava com infecção intestinal”.

"minha prima estava grávida, mas não era pra ter o bebê ainda. Foi ao hospital com dor, tomou remédio, depois o médico mandou pra casa. Tivemos que chamar a ambulância depois porque a dor não passava, e o neném nasceu dentro da ambulância a caminho do hospital de volta"

Também foram detectados conflitos sobre o uso da Língua Brasileira de Sinais por parte dos profissionais atuantes nas unidades.

\begin{abstract}
"estava em sala dando aula em uma escola para surdos, quando senti tontura e desmaiei. Os alunos chamaram um dos professores homens da escola para me levar ao hospital. Ele me carregou, colocou dentro do carro e fomos pra unidade de saúde. Chegando lá a unidade não tinha interprete de Libras, alias nenhuma tem. E como ele é surdo nenhum dos funcionários conseguiu entender o que ele estava dizendo. No fim ainda reclamaram de eu ter levado um surdo pra me ajudar, e dizendo que ele não sabia se comunicar. É um absurdo ouvir esse tipo de afirmação. Tenho certeza que ele sabia muito bem o que estava dizendo, o problema é deles que não entenderam"
\end{abstract}

As entrevista apontaram ainda a falta de conhecimento de profissionais que atuam nas unidades sobre as especificidades da deficiência auditiva e a maneira de se comunicar dos surdos, incluindo pessoal administrativo.

"uma das nossas alunas está internada no hospital. Eles não entendem que ela é surda. Estavam dando soro pra ela pelas mãos. Tivemos que ir lá pedir pra trocarem o soro de lugar porque ela não estava conseguindo se comunicar"

Sobre a dependência de um acompanhante interprete:

"sempre vou ao hospital com minha mãe. Ela não sabe Libras; só um pouco, mas entende o que eu digo. Se ela morre não consigo nem pensar, não vou ao hospital. Ninguém tem paciência”.

Todos os surdos entrevistados foram a favor da disponibilização de interpretes de Libras em ambiente hospitalares, mas alegam que o ideal seria que o médico soubesse a língua, pois quando se trata de assuntos mais pessoais os surdos se sentem intimidados com a presença de interprete. No Capítulo VII, artigo 18 da Lei de Acessibilidade: "O Poder Público implementará a formação de profissionais intérpretes de escrita em braile, língua de sinais e de guias-intérpretes, para facilitar qualquer tipo de comunicação direta à pessoa portadora de deficiência sensorial e com dificuldade de comunicação", incluindo os serviços de saúde. 
"queria que todos os médicos soubessem Libras. Alguns até podem ter interprete, mas pra algumas especialidades eu fico meio receoso porque é intimidade. Não quero que o interprete comente nada com ninguém. Fico com medo. É minha intimidade, como no caso de um urologista, um psicólogo, psiquiatra."

Já acerca das percepções sobre o que se constitui uma comunicação eficaz, do gestual ao físico: leitura labial ou escrita, identificou-se que, no atendimento médico, alguns profissionais, segundo relatos dos entrevistados, não conhecem as particularidades da surdez, e não têm clareza sobre os melhores métodos para constituir uma comunicação adequada. Já que, segundo Stefanelli (2005), o processo de comunicação configura-se como uma forma de compreender e compartilhar mensagens enviadas e recebidas. O modo como se dá este intercâmbio exercerá influência no comportamento das pessoas envolvidas.

"é difícil entender o médico quando ele não olha pra mim na consulta. Se ele fala de cabeça baixa eu não consigo entender porque não faço a leitura labial. Piora se ele usa barba. É melhor que todos os médicos não usem barba. Atrapalha"

Sobre a dificuldade de interação agregada à comunicação:

"Eu aprendi educação sexual na escola. Uma vez até fiquei perto de uma garota. A gente não sabia direito o que estava fazendo. Mamãe não me ensina essas coisas, o médico não entende o que digo. Ninguém ensina. Ainda bem que ensinaram na escola”

Entre outras normas, a ABNT, determina que o símbolo internacional de acesso deve indicar a acessibilidade aos serviços e identificar espaços, edificações, mobiliário e equipamentos urbanos onde existem elementos acessíveis ou utilizáveis por pessoas com de deficiência auditiva, contudo esta isto não é aplicado nas unidades de saúde, segundo os entrevistados.

"No hospital vi o simbolo internacional da surdez, uma vez. Fiquei feliz, pensei que alguém sabia Libras. Perguntei (escrevendo) na recepção se tinha interprete, a mulher respondeu que ela estava doente. Voltei outro dia, muito depois, disseram que a mulher estava de férias. Assim é dificil".

\section{CONCLUSÕES}

A maneira de as pessoas com deficiência auditiva terem acesso ao sistema público de saúde e a estrutura física dispensada pelas unidades foram estudadas neste artigo a fim de comparar se o que a Constituição Federal prevê juntamente com a legislação e as normas da 

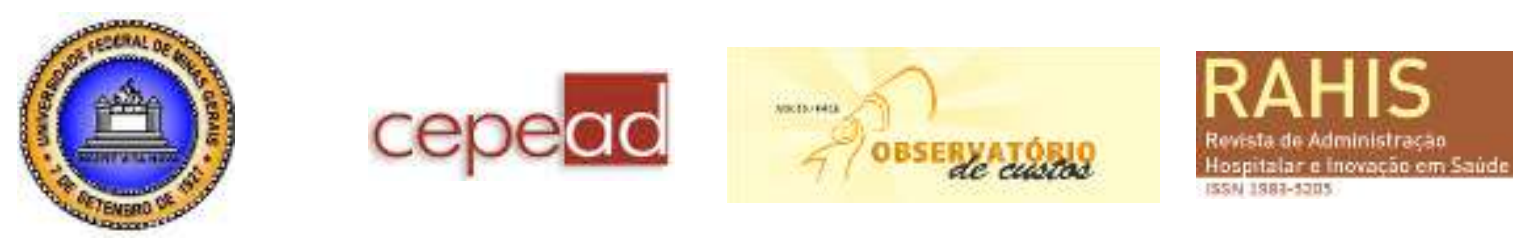

ABNT se aplicam às expectativas das pessoas com deficiência auditiva quando utilizam dos serviços de saúde.

O primeiro objetivo foi aplicar questionário em dez unidades de saúde, duas de cada uma das cinco zonas da cidade: norte, sul, leste, oeste e centro, sendo uma unidade de saúde (policlínica) administrada pelo Estado e uma Prefeitura em cada zona do município de Manaus. No entanto a pesquisa foi realizada em somente cinco das dez; nas demais os responsáveis pelas unidades se recusaram a responder às questões. A primeira impressão causada é o descaso com o bem estar do cidadão e ainda o desrespeito causado pela recusa de informações públicas. Diminui-se a amostra, mas o objetivo foi mantido, e de fato, nenhuma das unidades ou profissionais que nela atuam fizeram ou estão fazendo algum tipo de capacitação voltada ao atendimento de pessoas com deficiência auditiva, tampouco disponibilizam interpretes nos horários de atendimento. Este tipo de transtorno causa dependência do surdo em relação à figura de um acompanhante.

Constatou-se ainda que somente uma parte da equipe de receptivo das unidades sabe distinguir o que é a Língua Brasileira de Sinais, confundida com a escrita Braile, utilizada por deficientes visuais. Todos os entrevistados relataram que um dos maiores problemas enfrentados é a falta de comunicação, ou a equipe da unidade não conhece as especificidades da deficiência auditiva e a maneira ideal de se comunicar ou porque não conseguem ser compreendidos através do uso da Língua Brasileira de Sinais.

De fato, a inclusão não é uma ação instantânea, e os temas postos em discussão não vieram da inspiração individual, mas das colocações dos sujeitos da pesquisa. Então, as menores condições de atendimento nos serviços de saúde, de maneira independente (aos olhos do deficiente), já deveriam ter sido tomadas, por obrigação e por direito. E este descaso em vez de integrar, marginaliza mais ainda os desprovidos de audição. Por mais que se saiba que o processo de inclusão é construído lentamente, algumas propostas podem ser colocadas em prática de imediato, como levar a discussão acerca da comunicação com pacientes não verbais aos espaços de prática de saúde; ou se não for com a contratação de interpretes, que seja com cursos de capacitação em Língua Brasileira de Sinais para que se possa consolidar o primeiro passo prático além da lei.

\section{REFERÊNCIAS}

ABNT NBR 9050, Acessibilidade a edificações, mobiliário, espaços e equipamentos urbanos. Segunda edição, 2004.

BARDIN, L. Análise de conteúdo. Press universidade de france, 1977.

BESS, F. H. \& HEMES, L. E. Fundamentos de audiologia. Segunda edição, Porto Alegre: Artemed, 1998.

BISOL, Cláudia. Discursos sobre a Surdez: Deficiência, Diferença, Singularidade e Construção de Sentido. Rio Grande do Sul. Vol. 26, 2010. 


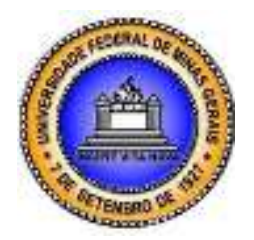

BRASIL. Coordenadoria Nacional para Integração da Pessoa Portadora de Deficiência. Acessibilidade , Brasília, Secretaria Especial dos Direitos Humanos, 2008.

CASTRO, S.S.; LEFÈVRE F.; LEFÈVRE, A.M.C; CESAR, C.L.G. Acessibilidade aos serviços de saúde por pessoas com deficiência. São Paulo. Rev. Saúde Pública 2011;45(1):99-105.

CHAVEIRO N, Barbosa MA. A surdez, o surdo e seu discurso. Rev. Eletrônica Enferm, 2004. Disponível em: http://www.fen.ufg.br/revista/revista6_2/surdez.html (Acesso em: 16 de Junho de 2012).

CHAVEIRO, N. Encontro do paciente surdo que usa língua de sinais com os profissionais da saúde. Dissertação (Mestrado) - Universidade Federal de Goiás, Programa de Pós-Graduação em Ciências da Saúde, Goiânia, 2007.

COSTA, L. S. M.; ALMEIDA, R. C. N.; MAYWORN, M. C.; ALVES, P. T. F.; BULHÕES, P. A. M.; PINHEIROS, V.M. O atendimento em saúde através do olhar da pessoa surda: avaliação e propostas. Revista Brasileira de Clínica Médica, Rio de Janeiro, n.7, p.166-170, 2009.

GIL, Antonio Carlos. Métodos e técnicas de pesquisa social / Antonio Carlos Gil. - 6. ed. São Paulo : Atlas, 2008.

GUNHER, H. Pesquisa qualitativa vs. pesquisa quantitativa: esta é a questão? Psicologia: Teoria e Pesquisa, 22(2), 201-209, 2006.

IEZZONI L.I.; O'DAY B.L.; KILLEEN M., et al. Communicating about health care: observations from persons who are deaf or hard of hearing. Ann Inter Med, 140:356-362, 2004.

MINAYO M.C; SANCHES O. Quantitativo-qualitativo: oposição ou complementaridade? Caderno de Saúde Pública 9(3):239-262, 1993.

RUSSO, I.C.P; SANTOS, T.M.M. Audiologia infantil. São Paulo: Cortez, 1989.

SARRAF, V. P. O conceito de acessibilidade ganha força entre os museus brasileiros. Rev. Cidadania. Ano 5, №. 40. Bunge. São Paulo, 2007. Disponível em:

<http://www.fundacaobunge.org.br/site/jornal_cidadania/edicoes/JC_40.pdf> Acesso em: 16 de Junho de 2012.

STEFANELLI M.C; CARVALHO E.C. A comunicação nos diferentes contextos da enfermagem. Barueri: Manole, 2005. 